\title{
Management of teaching processes using the Share point platform: A case study from the University of Split School of Medicine
}

\author{
Damir Sapunar*, Ivica Grković, Davor Lukšić, Matko Marušić
}

University of Split School of Medicine Split, Croatia

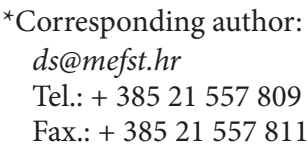

Received: 24 February 2016

Accepted: 12 April 2016

Key words: Medical education - Medical school - Organization • Teaching load.

\begin{abstract}
Objective. To develop a software tool that will combine teaching timetables with the generation of reports on teaching load. Methods. The University of Split School of Medicine project team and the external experts from the company LAMA, LLC. determined necessary functionalities and developed the software platform as an extension of the existing software solutions already in use by the Croatian academic community. Results. By combining comprehensive scheduling functionality with planned and performed teaching activities we determined the teaching load and realized automatic generation of payments for adjunct lecturers. The implementation required perfecting of the human resources services, brought about a manifold alleviation of the work of the entire school's administration and substantially increased the effectiveness of the quality management. The software is currently managing 54,676 teaching hours, 841 teaching staff member, 111 teaching rooms, 8 study programs, and 645 courses. Conclusion. The program resolved several administrative problems of the school and is an example of successful implementation of IT technology in medical school management.
\end{abstract}

\section{Introduction}

Medical education in Croatia is based on a six-year integrated program (1) offered in four medical schools at the Universities of Osijek, Rijeka, Split, and Zagreb. All four schools are a part of public universities and are funded by the Ministry of Science, Education and Sports. The process of budget allocation to an individual medical school is not a result of a defined funding system but is largely based on old practice inherited from times before Croatia became an independent country. Currently there are no clear monetary allocation principles, and the documents from which the schools' bud- gets can be determined are scarce (2). If the budget is considered a function of the cost per graduating student, the largest amount is spent at the medical school in Zagreb (US\$ 90,000 per student, for the six-year study program). The amount per graduating student in US dollars in Rijeka is \$ 40,000, \$30,000 in Split, and \$29,000 in Osijek (3). These amounts and the lack of budget allocation principles are still not provoking serious discussion and analysis in the respective professional circles.

The only fixed factor that directly affects the above mentioned costs is the number and structure of employed faculty members. Salaries make up an average of $50 \%$ to $60 \%$ of 
the expenditures $(54 \%$ at the medical school in Split in 2009, data in the possession of the authors). Because the main criterion for the opening of new positions is the teaching load, there is a serious need for the transparent determination of the teaching load for each academic staff member, department, and the school as a whole. One would therefore expect that schools, universities, and the relevant Ministry officials would seriously scrutinize teaching loads. The need for a precise analysis of the teaching load is additionally emphasized by the phenomenon of professorial "moonlighting" (the practice of academics teaching at several schools and receiving salaries from all of them), which has become a serious problem in the academic community (4).

Without a proper information technology (IT) solution it is quite difficult to determine the total teaching load at a particular school and, consequently the budget for the salaries. The budget calculation is further complicated by the additional cost of adjunct lecturers, mainly clinicians who teach part-time.

When confronted with this problem, we reckoned that the IT approach would be the right strategy to solve the proper allocation of salaries based on teaching load. The main software platform for the management of educational processes in Croatia is the Information System for Higher Education (ISVU) (5), and has been in use at the medical school in Split since 2007. However, this platform does not assist in determining either teaching loads or associated costs. Also, various software solutions used in other Croatian medical schools provide only scheduling capabilities without options for calculating the teaching load. The lack of this important functionality required an extremely tedious and relatively imprecise "manual" labor by the schools' administration to compose the reports required by the university and the Ministry of Science, Education and Sports, which subsequently led to the imprecise determination of budget allocation.

\section{Methods}

We decided to develop a software platform that will enable us to combine teaching timetables with the generation of reports on teaching load, planned and performed teaching activities, and the automatic generation of payments for adjunct lecturers. The project team at the University of Split School of Medicine determined the necessary functionalities for the platform and engaged LAMA, LLC, an external IT company, with the aim of developing new software that will be compatible with the existing ISVU software solution.

The requirements for the new program are from a business process analysis performed at our school (6) and divided into two main functionalities (Figure 1). The first functionality addressed planning and scheduling of teaching and extracurricular activities, generation of a web-based timetable of all teaching/space allocation modalities: room, teacher, student group, type of teaching (lecture, seminar, practical) and topic - all on an a daily and hourly basis.. The second functionality was related to the key problem of the calculation of teaching load, generation of the reports on planned and performed teaching activities and the automatic generation of payment contracts for adjunct lecturers or teachers (Figure 1). 


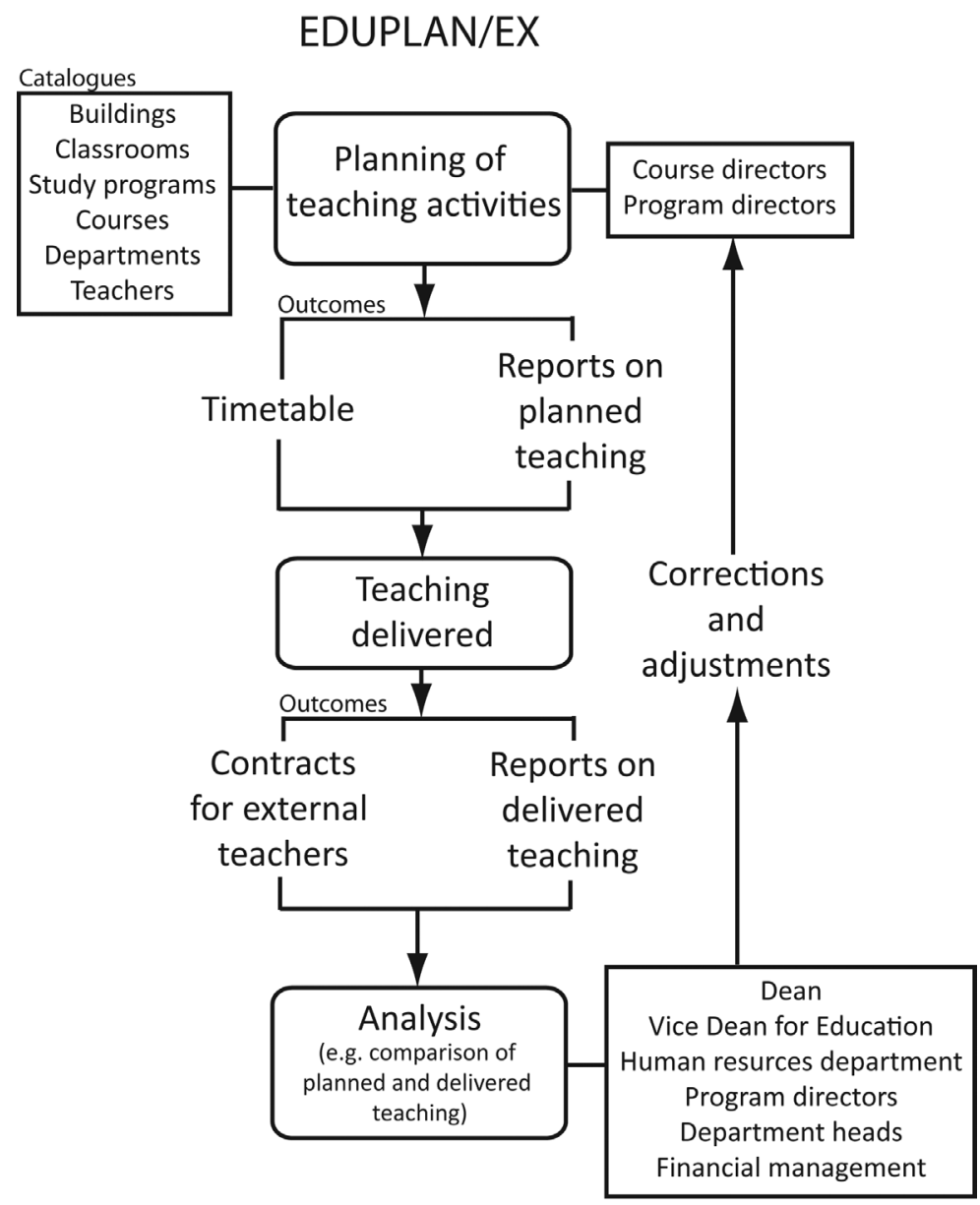

Figure 1 The functionalities of the software tool that combines teaching timetables with generation of reports on teaching load at the University of Split School of Medicine. By combining a comprehensive scheduling functionality with planned and performed teaching activities, we achieved the main goal of the program, i.e., determination of the teaching load and automatic generation of payments for adjunct lecturers or teachers.

\section{Results}

The result of the project was the development of the EduPlan/EX software based on Microsoft Sharepoint, SQL and ASP.NET technologies implemented through a virtualized environment on two Microsoft Windows Server. Usage of MS Active Directory repository allows authentication and authorization based on previously granted user rights by system administrator and distinguished user roles. Access to the EduPlan/ EX application is through a web browser.
The system has an internal fully functional interface for authenticated faculty staff, an external presentation interface with limited functionality and read only access at http:// nastava.mefst.hr:10000/.

The first step in implementation of the program is completing the main catalogues (list or record of buildings, teaching rooms, departments and teachers). Administrators from the Office of Student Affairs and the IT Department entered catalogue data.

The teachers/administrators selected by a particular department execute the teaching 
timetable. The planning, particularly in the block-based organization of the curriculum, is a demanding and complex task, which requires a specific user-friendly computer interface. Planning includes entry of all elements of the teaching based on one teaching hour as the core unit that comprises course, topic, time, teaching room, teacher, type of the teaching, and the student group. Based on entered data, the system provides real time availability information for all teaching locations. This functionality provides a key point of resource sharing and the efficient management of teaching resources.

Teaching reports can be automatically produced for all these entries: teaching load for an individual teacher, course, department, and for the school as a whole. Hours of lectures, seminars, and practical classes are all exportable as lists into different formats such as Portable Document Format (pdf), Microsoft (MS) Word, or MS Excel.

Our team entered the complete plan for all courses into the program before the start of the academic year. At the inception of this program (academic year 2011/12), planning and entering data required a lot of time and effort since we had to deal with a large number of teaching hours. However, in subsequent years the work was much less demanding, because the educational framework did not change and the program allows copy and paste changes of dates, teacher names, and lectures.

Currently, the program deals with 54,676 teaching hours distributed over four integrated programs (medicine, dental medicine, pharmacy, medical studies in English), and three postgraduate (doctoral) programs. However, the application of this program for the first time in 2011 had additional outcomes. First, we discovered discrepancies between the educational program of several subjects and their plans for the current school year, as well as numerous discrepancies between the teaching plans and data entered in the program. This clear-cut and quantitative insight enabled us to synchronize subsequently the data to a satisfactory level. Second, we were able to identify departments with high teaching loads from adjunct faculty, distribute that teaching load to employed faculty, and by doing so reduced the costs of adjunct lecturers.

Currently, the EduPlan/EX contains 841 teaching staff members, 111 teaching rooms, 8 study programs, and 645 courses. Notably, our business solution program had the highest business value recognition at the Windays 2012 conference (7).

\section{Discussion}

With EduPlan/EX we achieved all planned functionalities and resolved one of the main administrative problems in the management of resources at our school. The scheduling functionality allowed us to have precise timetables several months before the start of the academic year, to provide online access to timetables, and to avoid conflicts in classroom booking. The biggest tangible gain was the drastic reduction in administrative work to collect data on the teaching workload from all teachers all of whom have numerous variations in their contracts, academic status, planned and completed teaching hours. We also achieved a reduction in the automatic generation of contracts for adjunct lecturers or teachers (about 500 professionals). Weeks of exhausting and proneto-error work by several offices to compose hundreds of employment contracts to achieve contractal payments are now shortened to a direct printing of the contracts from to the EduPlan/EX program. The satisfaction of the finance and education administrative staff is worth noting in this report. The lack of quantitative outcomes following the implementation of the EduPlan/EX program was a limitation of the study. However, the quantification can be considered unnec- 
essary when we know that all presented outcomes were unavailable before implementation of the program.

The program allowed us to keep track of the changes in the planned teaching activities due to engagement of different teachers. This was necessary because all teachers cannot plan their extracurricular or other obligations the whole year in advance. The changes (replacing the names of absent teachers with those who substituted them) turned out to be relatively frequent and difficult to manage on time, mainly due to the lack of control of the communication between the teachers in question and persons in charge of the EduPlan/EX in a specific department. Endowing the teachers with personal electronic cards, which they would activate at the beginning of the lecture/seminar/practical class, so that subsequently the program automatically changes the names in its database, provides an elegant solution. An additional way of registering a teacher could be through logging into a classroom computer or by a smartphone, all with the ultimate goal of full automatization. The expansion of the currently used version of the program is aiming in that direction.

\section{What is already known on this topic}

Currently there are no well-defined principles for budget allocation to Croatian medical schools while salaries make up on average $50 \%$ to $60 \%$ of the expenditures. The teaching load is the main argument for opening new positions in the Croatian academic community. There are no information technology (IT) solutions for the automatic calculation of the teaching load.

\section{What this study adds}

This study describes the development of a software tool that combines teaching timetables with the generation of reports on teaching load. The combination of comprehensive scheduling functionality with planned and performed teaching activities allows the determination of the teaching load and automatic generation of payments for adjunct lecturers or teachers. The program resolved several administrative problems at the medi- cal school. With the success of our resource saving software in medical school management, perhaps other medical schools in the region may benefit from this software as well.

Acknowledgement: The authors acknowledge the LAMA, LLC company (Split, Croatia) for providing technical support for the execution of the project, and Professor Ana Marušić for critical review of the report.

Authors' contribution: Conception and design: DS, IG, DL, and MM; Acquisition, analysis and interpretation of data: DS, IG, DL and MM; Drafting the article: DS; Revising it critically for intellectual content: IG, DL and MM; Approval of final version to be published: DS, IG, DL, and MM.

Conflict of interest: The authors declare that they have no conflict of interest.

\section{References}

1. Grkovic I, Sapunar D, Marusic M. Ways to address the challenges of a modern medical curriculum: Living academic medicine at the University of Split, School of Medicine. Acta Med Acad. 2012;41(1):7-17.

2. Maslov Kruzicevic S, Barisic KJ, Banozic A, Esteban CD, Sapunar D, Puljak L. Predictors of attrition and academic success of medical students: a 30-year retrospective study. PloS One. 2012;7(6):e39144.

3. Petrašić A, Janković S, Marušić M. Why is the price of a student education three times hights in Zagreb than in Split? [in Croatian]. Liječničke novine. $2011 ;(96): 65$.

4. Marušić $M$. The equilibrium of the low quality [in Croatian]. Školske novine. 2001;30(4):3.

5. Information system of higher education institutions - ISVU [homepage on the Internet]. Zagreb: University of Zagreb, University Computing Centre - SRCE [cited 2016 Feb 10]. Available from: http://www.isvu.hr/.

6. Sapunar D, Grković I, Lukšić D, Marušić M. The business process management software for successful quality management and organisation: A case study from the University of Split School of Medicine. Acta Med Acad. 2016;45;1:26-33.

7. EDUPLAN/EX - A solution with best business value [homepage on the Internet]. Split: Lama [cited 2016 Feb 10]. Available from: http://www. lama.hr/rjesenja/aplikativna-rjesenja/eduplan/. 